\title{
STRATEGI KOMUNIKASI KESEHATAN BAGI TINGKAT KEPATUHAN PASIEN INSTALASI REHABILITASI MEDIK RSUP PROF. KANDOU MANADO
}

\author{
Felicia Aotama, Apriles Mandome \\ Universitas Sariputra Indonesia Tomohon, Sulawesi Utara \\ felicia.aotama@unsrittomohon.ac.id,apriles@unsrittomohon.ac.id
}

\begin{abstract}
Abstrak
Kepatuhan seorang pasien sangat berperan besar dalam proses kesembuhan. Namun demikian dalam kenyataannya, tingkat kepatuhan pasien justru sangat kurang atau rendah. Tentu saja hal ini menjadi persoalan serius bagi penanganan pasien tersebut. Fenomena rendahnya tingkat kepatuhan pasien juga terjadi di Rumah Sakit Umum Pusat Prof. Kandou Manado, khususnya pada Instalasi Rehabilitasi Medik sebagai salah satu bagian yang ada di RSUP Prof. Kandou Manado. Tingkat kepatuhan pasien yang rendah tentu saja dipengaruhi oleh banyak faktor. Salah satu faktor yang dianggap menjadi penyebab rendahnya tingkat kepatuhan pasien adalah kurangnya pemahaman atau pengetahuan pasien terhadap isu-isu kesehatan yang dihadapinya. Hal ini didorong oleh kurang informasi yang diberikan kepadanya. Karena itu, pemberian informasi melalui komunikasi kesehatan merupakan salah satu solusi yang penting menghadapi fenomena rendahnya tingkat kepatuhan pasien. Oleh karena itu penelitian ini mencoba mengkaji dan menganalisa strategi komunikasi kesehatan bagi tingkat kepatuhan pasien Instalasi Rehabilitasi Medik RSUP Prof. Kandou Manado. Untuk mencapai tujuan penelitian maka penelitian ini menggunakan metode deskriptif kualitatif. Data dikumpulkan melalui observasi, wawancara dan studi dokumenter. Data yang didapat kemudian diolah melalui teknik analisis data yang dibagi dalam tiga tahapan, yakni reduksi data, penyajian data dan penarikan kesimpulan. Untuk lebih meyakinkan hasil dari penelitian ini, maka data yang telah didapat juga akan diverifikasi melalui tiga tahap, yakni triangulasi, member checking dan expert opinion sehingga simpulan dari hasil penelitian ini dapat dipertanggungjawabkan secara ilmiah dan dapat memberikan kontribusi untuk meningkatkan tingkat kepatuhan pasien di Instalasi Rehabilitasi Medik RSUD Prof. Kandou.
\end{abstract}

Kata kunci: Kepatuhan, pasien, rehabilitasi medik, komunikasi kesehatan.

\begin{abstract}
A patient's compliance plays a big role in healing process. However, in reality, the level of patient adherence is actually very poor or low. Of course this is a serious problem in patients' handling process. the phenomenon of low patient adherence also occurs at Prof. Kandou General Hospital, especially in Medical Rehabilitation Installation.The low level of patient adherence is of course influenced by many factors. One of the factors that is considered to be the cause of the low level of patient adherence is patients' lack of understanding or knowledge on the health issues they face. This is driven by the lack of information that is given to them. Therefore, providing information through health communication is an important solution in dealing with the phenomenon of low patient adherence. Therefore, this study tried to analyze the health communication strategies for improve the level of patient adherence in the Medical Rehabilitation Installation at Prof. Kandou General Hospital.To achieve the research objectives, a qualitative descriptive method had been chosen. Data were collected through observation, interviews and documentary studies. The data obtained is then processed through data analysis techniques which are divided into three stages, which are data reduction, data presentation and conclusion drawing. To be more convincing about the results of this study, the data that had been obtained was verified through three stages, namely triangulation, member checking and expert opinion so that the conclusions from the results of this study can be scientifically accounted for and can contribute to increase the level of patient adherence in the Medical Rehabilitation Installation at Prof. Kandou General Hospital.
\end{abstract}

Keywords: Adherence, patient, medical rehabilitation, health communication 


\section{PENDAHULUAN}

Perilaku tidak patuh dalam kehidupan sehari-hari sudah biasa. Namun, perilaku tidak patuh dalam lingkup kesehatan sangat berbahaya. Apalagi tidak patuh dalam mengikuti petunjuk dokter dapat menyebabkan sejumlah akibat yang tidak diinginkan seperti: sakit bertambah lama atau kondisi medis memburuk, atau bahkan kematian. Hal ini menjadi fenomena pada semua rumash sakit, tidak terkecuali pada Instalasi Rehabilitasi Rumah Sakit Umum Pusat Prof. Kandou Malalayang. Sebagai sebuah rumah sakit rujukan dengan tipe A, maka tentu saja hal ini dapat menjadi persoalan serius. Bukan saja hanya bagi pasien itu sendiri tetapi juga bagi citra atau nama baik RSUP Prof. Kandou Manado secara umum dan bagi Instalasi Rehabilitasi Medik pada khususnya. Sebab sejatinya rumah sakit harus mampu memberikan pelayanan yang berkualitas kepada siapapun yang datang dan berobat. Seperti yang diatur dalam Peraturan Menteri Kesehatan Republik Indonesia Nomor 340/MENKES/PER/III/2010. Disamping itu sebagai sebuah rumah sakit yang memiliki fasilitas terlengkap dan terbesar bukan saja di kota Manado melainkan di Indonesia Timur maka syogyanya RSUP Prof. Kandou Manado harus meminimalisasi dampak negative dari ketidakpatuhan pasien yang ada di Intalasi Rehabilitasi Medik RSUP Prof. Kandou Manado.

Oleh karena itu diperlukan sebuah cara yang solutif terhadap persoalan tingkat kepatuhan pasien tersebut. Sebab, kepatuhan pasien yang rendah sering bersumber dari ketidaktahuan dan kesalahpahaman atas berbagai informasi kesehatan yang diterima. Dalam kenyataannnya banyak juga pasien yang tidak patuh atau tingkat kepatuhannya sangat rendah bukan karena para pasien ini tidak mau mengikuti petunjuk dokter atau tenaga medis, melainkan karena ketidaktahuan yang diakibatkan kurangnya informasi yang diterima.

Pada hakikatnya, program rehabilitas adalah bentuk pelayanan kesehatan yang terpadu dengan pendekatan medik, psikososial, edukasional-vokasional yang bertujuan mencapai kemampuan fungsional semaksimal mungkin dan mencegah serangan berulang. Dalam pelayanan rehabilitasi ini merupakan pelayanan dengan pendekatan multidisiplin yang terdiri dari dokter ahli rehabilitasi medik, perawat, fisioterapis, terapi okupasional, pekerja sosial medik, psikolog serta klien dan keluarga turut berperan. Maka dari itu, untuk mencapai hasil maksimal yaitu kesembuhan seorang pasien memang diperlukan kepedulian dan perhatian serius bukan saja dari dokter dan tenaga medis tetapi juga pasien bahkan keluarga dan semua orang yang terlibat dalam proses pengobatan sang pasien.

Salah satu upaya serius yang dapat dilakukan untuk meningkatkan kepatuhan pasien pada Instalasi rehabilitasi Medik RSUP Prof. Kandou Manado adalah melalui komunikasi kesehatan. Secara sederhana komunikasi kesehatan adalah bagian dari komunikasi antar 
manusia yang memiliki fokus pada bagaimana seorang individu dalam suatu kelompok/masyarakat menghadapi isu-isu yang berhubungan dengan kesehatan serta berupaya untuk memelihara kesehatannya. Komunikasi kesehatan adalah usaha yang sistematis untuk mempengaruhi secara positif perilaku kesehatan individu dan komunitas masyarakat, dengan menggunakan berbagai prinsip dan metode komunikasi baik komunikasi interpersonal, maupun komunikasi massa. Dengan demikian tujuan penelitian ini adalah menganalisis penggunaan komunikasi kesehatan sebagai strategi bagi peningkatan kepatuhan pasien Instalasi rehabilitasi Medik RSUP Prof. Kandou Manado dan memberikan landasan konseptual terhadap penggunaan komunikasi kesehatan bagi peningkatan kepatuhan pasien.

\section{TINJAUAN PUSTAKA}

\section{Intalasi Rehabilitasi Medik}

Rehabilitasi Medik adalah ilmu pengetahuan kedokteran yang mempelajari masalah atau semua tindakan yang ditujukan untuk mengurangi atau menghilangkan dampak keadaan sakit, nyeri, cacat dan atau halangan serta meningkatkan kemampuan pasien mencapai integrasi sosial. Menurut Keputusan Menteri Kesehatan Nomor 378/Menkes/SK/IV/2008 tentang Pedoman Pelayanan Rehabilitasi Medik Di Rumah Sakit, yang dimaksud dengan Rehabilitasi Medik adalah pelayanan kesehatan terhadap gangguan fisik dan fungsi yang diakibatkan oleh keadaan/kondisi sakit, penyakit atau cedera melalui paduan intervensi medik, keterapian fisik dan atau rehabilitatif untuk mencapai kemampuan fisik yang optimal.

Tujuan pelayanan rehabilitasi medik sendiri menurut Keputusan Menteri Kesehatan Nomor 378, adalah mengatasi keadaan/kondisi sakit melalui paduan intervensi medik, keterapian fisik, keteknisian medik dan tenaga lainnya yang terkait, mencegah komplikasi akibat tirah baring dan atau penyakitnya yang mungkin membawa dampak kecacatan, emaksimalkan kemampuan fungsi, meningkatkan aktifitas dan partisipasi pada difabel.

Pelayanan Rehabilitasi Medik di Rumah Sakit meliputi seluruh upaya kesehatan pada umumnya, yaitu promotif, preventif, kuratif dan rehabilitatif ${ }^{1}$.

a) Upaya Promotif berupa penyuluhan, informasi dan edukasi tentang hidup sehat dan aktifitas yang tepat untuk mencegah kondisi sakit

b) Upaya Preventif yaitu edukasi dan penanganan yang tepat pada kondisi sakit/penyakit untuk mencegah atau meminimalkan gangguan fungsi atau resiko kecacatan.

\footnotetext{
${ }^{1}$ Keputusan Menteri Kesehatan Nomor 378/Menkes/SK/IV/2008 tentang Pedoman Pelayanan Rehabilitasi Medik Di Rumah Sakit. Jakarta: Kementerian Kesehatan Republik Indonesia
} 
c) Upaya Kuratif berupa penanganan melalui paduan intervensi medik, keterapian fisik dan upaya rehabilitatif untuk mengatasi penyakit/kondisi sakit untuk mengembalikan dan mempertahankan kemampuan fungsi

d) Upaya Rehabilitatif berupa penanganan melalui paduan intervensi medik, keterapian fisik, keteknisian medik dan upaya rehalibitatif lainnya melalui pendekatan psikososio-edukasi-okupasi-vokasional untuk mengatasi penyakit/kondisi sakit yang bertujuan mengembalikan dan mempertahankan kemampuan fungsi, meningkatkan aktifitas dan peran serta/partispasi di masyarakat.

\section{Intalasi Rehabilitasi Medik RSUP Prof. Kandou Manado}

Rumah Sakit Umum Pusat Prof. Dr. R.D. Kandou Manado adalah Rumah Sakit Umum milik Kementrian Kesehatan RI, berada di Kota Manado Provinsi Sulawesi Utara. Saat ini kapasitas rumah sakit memiliki 741 tempat tidur dengan rata-rata tingkat hunian 84,67\% per tahun. Jangkauan pelayanan rumah sakit bukan hanya untuk Provinsi Sulawesi Utara tetapi juga meliputi wilayah Indonesia Bagian Timur ${ }^{2}$.

RSUP Prof. Dr. R. D. Kandou Manado adalah Institusi Pelayanan Kesehatan yang menyelenggarakan kegiatan pelayanan kesehatan perorangan secara paripurna dengan mengutamakan pengobatan dan pemulihan tanpa mengabaikan peningkatan kesehatan dan pencegahan penyakit yang dilaksanakan melalui penyediaan pelayanan rawat inap, rawat jalan, gawat darurat dan tindakan medis ${ }^{3}$. Instalasi Rehabilitasi Medik merupakan salah satu bagian yang terpisahkan dalam pelayanan kesehatan yang dilakukan di RSUP Prof. Kandou Manado. Sebagaimana pelayanan Rehabilitasi Medik lainnya, maka fungsi, tugas dan tanggungjawab Instalasi Rehabilitasi Medik RSUP Prof. Kandou Manado juga mengacu pada Peraturan Menteri Kesehatan Republik Indonesia Nomor 340/MENKES/PER/III/2010, Keputusan Menteri Kesehatan Nomor 378/Menkes/SK/IV/2008 serta Rencana Strategis Bisnis Tahun 2015 - 2019 RSUP Prof. Kandou Manado.

Mengacu pada aturan-aturan dan rencana strategis yang ada, maka sesungguhnya keberadaan Instalasi rehabilitasi Medik RSUP Prof. Kandou Manado adalah sebagai upaya menghadirkan pelayanan kesehatan yang terbaik bagi masyarakat.

\footnotetext{
${ }^{2}$ Rencana Strategis Bisnis Tahun 2015 - 2019 Rumah Sakit Umum Pusat Prof. Kandou Manado, Revisi III. 2015. Manado: RSUP Prof. Kandou.

${ }^{3}$ Rencana Strategis Bisnis Tahun 2015 - 2019.
} 


\section{Komunikasi Kesehatan dan Kepatuhan Pasien}

Ada beberapa macam terminologi yang biasa digunakan dalam literatur untuk mendeskripsikan kepatuhan pasien diantaranya compliance, adherence, dan persistence. Menurut Kozier kepatuhan adalah perilaku individu (misalnya: minum obat, mematuhi diet, atau melakukan perubahan gaya hidup) sesuai anjuran terapi dan kesehatan ${ }^{4}$. Secara umum komunikasi kesehatan dapat didefinisikan sebagai komunikasi antarmanusia yang berkaitan dengan isu-isu kesehatan. Secara lebih mendalam dapat dikatakan bahwa komunikasi kesehatan merupakan proses komunikasi yang bukan hanya melibatkan pesan kesehatan dan unsur-unsur tetapi juga peserta komunikasi yang terlibat didalamnya, yaitu dokter, pasien, perawat, profesional kesehatan, atau orang lain.

Menurut Liliweri, Komunikasi kesehatan adalah usaha yang sistematis untuk mempengaruhi secara positif perilaku kesehatan individu dan komunitas masyarakat, dengan menggunakan berbagai prinsip dan metode komunikasi baik komunikasi interpersonal, maupun komunikasi massa. Selain itu, komunikasi kesehatan juga dipahami sebagai studi yang mempelajari bagaimana cara menggunakan strategi komunikasi untuk menyebarluaskan informasi kesehatan yang dapat mempengaruhi individu dan komunitas agar dapat membuat keputusan yang tepat berkaitan dengan pengelolaan kesehatan ${ }^{5}$. Oleh karena komunikasi kesehatan bertujuan meningkatkan kesadaran individu terhadap isu-isu kesehatan, maka sesungguhnya komunikasi kesehatan memegang peranan yang sangat penting.

Kepatuhan pasien terhadap saran medis yang diberikan dokter maupun tenaga medis sangat dipengaruhi oleh komunikasi kesehatan. Menurut Metta Rahmadiana, terdapat dua hal yang keduanya menjadi faktor penting yang mempengaruhi kepatuhan pasien terhadap saran medis yang diberikan. Pertaman, pasien harus terlebih dahulu memahami (understand) isuisu kesehatan atau masalah-masalah kesehatan yang dihadapi. Untuk itu ia harus mampu menafsirkan dan memahami semua informasi kesehatan yang dikomunikasikan oleh tenaga medis pada dirinya. Kedua, Pasien harus mampu mengingat (memorize) saran medis yang diberikan. Bila dalam mengkomunikasikan informasi seputar kesehatan pasien, para ahli medis tidak menggunakan istilah (jargon) medis yang sulit dipahami oleh pasien umum dan informasi yang diberikan tidak terlalu banyak dan rumit, maka pasien dapat dengan mudah

\footnotetext{
${ }^{4}$ Kozier. Erb, Berman. Snyder. 2010. Buku Ajar Fondamental Keperawatan: Konsep, Proses \& Praktik, Volume : 1, Edisi : 7. Jakarta:EGC.

${ }^{5}$ Liliweri, Alo. 2008. Dasar-Dasar Komunikasi Kesehatan. Yogyakarta: Pustaka pelajar
} 
mengingat kembali semua informasi kesehatan (saran medis) yang telah disampaikan untuk dirinya. Misalnya, kapan minum tertentu dan berapa dosis untuk setiap obat dan sebagainya ${ }^{6}$.

Dalam prakteknya, terdapat beberapa bentuk komunikasi kesehatan yang sering diterapkan dan terkait dengan kepatuhan pasien paling tidak terdapat dua bentuk komunikasi yang dapat dilakukan:

1) Komunikasi kesehatan dengan pasien/penderita

Dalam komunikasi kesehatan dengan seorang pasien maka tentu saja pesan yang hendak disampaikan adalah masalah kesehatan yang dihadapi pasien, situasi dan bentuk penanganan yang dapat dan akan dilakukan, hasil, informasi bagaimana memaksimalkan perawatan, apa obat yang diberikan, bagaimana aturan mengenai obat dan makanan dan lain sebagainya.

2) Komunikasi kesehatan dengan pihak keluarga

Komunikasi kesehatan dengan pihak keluarga juga harus diperhatikan. Jika ada anggota keluarga yang menderita sakit dan harus menjalani serangkaian terapi dan pengobatan, keseluruhan proses ini harus diketahui dan dipahami oleh pihak keluarga. Karena yang seringkali terjadi, setiap kali anggota keluarga akan menjalani terapi muncul reaksi emosional dan psikologis tertentu. Jika pihak keluarga tidak memberikan penjelasan informasi yang tepat tentang rangkaian terapi pengobatan yang harus dijalani, besar kemungkinan anggota keluarga yang sakit ini menolak untuk menjalani terapi yang harus dilalui.

\section{METODE PENELITIAN}

Metode yang dipakai dalam penelitian ini adalah deskriptif kualititaf. Metode deskriptif kualitatif sendiri adalah metode penelitian yang berlandaskan pada filsafat postpositivisme yang biasanya digunakan untuk meneliti pada kondisi obyektif alamiah dimana peneliti sendiri berperan sebagai instrument kunci. Oleh karena itu, berdasarkan karakteristik tersebut maka dalam penelitian ini, peneliti akan bertindak sebagai instrument kunci yang secara langsung mencari data di lapangan dan kemudian menguraikan hasil penelitian berdasarkan data yang didapatkan. Lokasi penelitian ini adalah Kota Manado yang mana dalam hal ini adalah Instalasi Rehabilitasi Medik RSUP Prof. Kandou Manado. Subyek dalam penelitian ini yang juga sumber data dipilih berdasarkan pendekatan purposive

\footnotetext{
${ }^{6}$ Rahmadiana, M., 2012. Komunikasi 1/Desember 2012
}

Kesehatan: Sebuah Tinjauan. Jurnal Psikogenesi. Vol. 1, No. 
sampling dan key person ${ }^{7}$. Berdasarkan cara ini maka subyek-subyek yang dimaksud adalah dokter ahli rehabilitasi medik, fisioterapi, dokter umum, psikolog serta pasien yang ada di Instalasi rehabilitasi Medik RSUP Prof. Kandou Manado.

Adapun teknik pengumpulan data yang dilakukan dalam penelitian ini melalui data primer. Data primer diperoleh dengan melakukan observasi dilakukan langsung di lapangan yang dalam hal ini pada para dokter ahli rehabilitasi medik, fisioterapi, dokter umum, psikolog serta pasien yang ada di Instalasi rehabilitasi Medik RSUP Prof. Kandou Manado. Kemudian melakukan wawancara secara terukur dengan bentuk wawancara tertutup kepada dokter ahli rehabilitasi medik, fisioterapi, dokter umum, psikolog serta pasien yang ada di Instalasi rehabilitasi Medik RSUP Prof. Kandou Manado. Serta studi dokumen terhadap dokumen penelitian mengenai komunikasi kesehatan dan tingkat kepatuhan pasien serta dokumen-dokumen tambahan lainnya yang terkait dengan tema penelitian.

Analisis data menggunakan dua pendekatan yaitu analisis data sebelum di lapangan dan analisis data selama di lapangan. Hal ini sejalan dengan apa yang diungkapkan oleh Sugiono bahwa dalam penelitian kualitatif proses analisis data berlangsung sebelum peneliti ke lapangan, kemudian selama di lapangan dan setelah di lapangan. Analisis data sebelum di lapangan akan dilakukan dengan cara melakukan analisis terhadap berbagai data yang berkaitan komunikasi kesehatan serta interaksi yang terjadi antara dokter serta tenaga medis dengan pasien yang ada pada Instalasi Rehabilitasi Medik RSUP Prof. Kandou Manado. Sedangkan analisis data selama di lapangan akan dilakukan secara interaktif dan berlangsung terus menerus sampai tuntas sehingga datanya sudah jenuh sebagaimana yang diungkapkan oleh Miles dan Huberman ${ }^{8}$. Oleh karena itu hal ini akan dilakukan melalui tiga unsur: reduksi data, penyajian data dan penarikan kesimpulan.

Metode penelitian ini adalah metode kualitatif, salah satu unsur penting yang diperlukan agar data dan kesimpulan yang dihasilkan dapat dipertanggungjawabkan adalah melakukan verifikasi data. Verifikasi data dalam penelitian kualitatif merupakan upaya pemeriksaan terhadap akurasi hasil penelitian dengan menerapkan prosedur-prosedur tertentu ${ }^{9}$. Karena itu verifikasi data dalam penelitian akan dilakukan dalam tiga tahap yaitu: triangulasi, member checking dan expert opinion.

\footnotetext{
${ }^{7}$ Bungin, B., 2010. Penelitian Kualitatif. 1 ed. Jakarta: Kencana.

${ }^{8}$ Bungin, B., 2010.

${ }^{9}$ Creswell, J. W., 2010. Research Design Pendekatan Kualitatif, Kuantitatif, dan. Yogyakarta: Pustaka Pelajar.
} 


\section{PEMBAHASAN}

Tingkat kepatuhan pasien menjadi sebuah sikap penting dalam proses penyembuhan terhadap pasien. Sebab perilaku tidak patuh dalam lingkup kesehatan sangat berbahaya. Apalagi tidak patuh dalam mengikuti petunjuk dokter dapat menyebabkan sejumlah akibat yang tidak diinginkan seperti: sakit bertambah lama atau kondisi medis memburuk, atau bahkan kematian. Hal ini menjadi fenomena pada semua rumash sakit, tidak terkecuali pada Instalasi Rehabilitasi Medik Rumah Sakit Umum Pusat Prof. Kandou Manado.

Dalam sebulan rerata Instalasi Rehabilitasi Medik RSUP Prof. Kandou Manado melakukan rawat inap kepada 400 pasien dan rawat jalan kepada kurang lebih 800 pasien yang ditangani oleh para dokter dan fisioterapi yang ada hingga total ada sekitar 1200 pasien yang menjalani perawatan rehabilitasi medik dalam satu bulan. Dari jumlah pasien tersebut, jumlah pasien pria sebanyak 532 pasien dan perempuan sebanyak 668 pasien. Dari 60 pasien yang ada di Instalasi Rehabilitasi RSUP Prof. Kandou Manado data menunjukkan untuk pasien berusia 1-25 tahun sebanyak 123 orang, usia 25 - 50 tahun sebanyak 378 orang dan sisanya atau sebanyak 699 pasien berusia diatas 50 tahun.
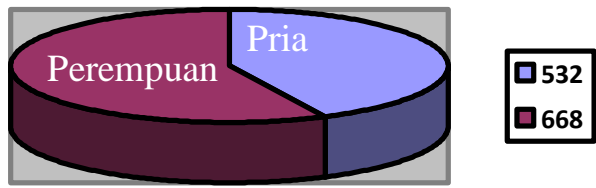

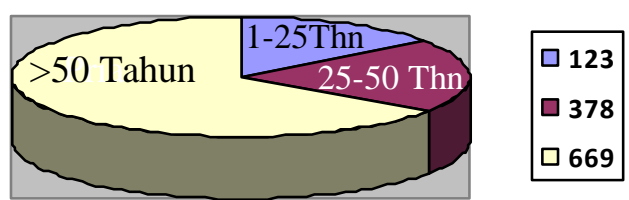

Gambar 1.

Perbandingan Jumlah Pasien berdasarkan Jenis Kelamin dan usia

Dari 1200 pasien sebanyak 315 pasien memiliki masalah kesehatan dengan kategori ringan, dengan kategori sedang sebanyak 695 pasien dan dengan kategori berat sebanyak 190 pasien.
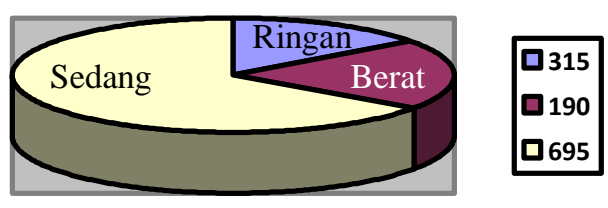

Gambar 2.

Perbandingan Jumlah Pasien berdasarkan kategori sakit yang diderita

Dalam penelitian ini dilakukan wawancara terhadap narasumber yang dipilih dari antara dokter/fisioterapi yang ada di Instalasi Rehabilitasi Medik RSUP Prof. Kandou 
Manado. Oleh karena masa pandemic Covid 19 yang dialami maka wawancara dilakukan secara online (video call whatsapp) dan melalui sambungan telepon. Dari wawancara yang dilakukan ditemukan hasil bahwa rerata setiap minggu komunikasi yang dilakukan dokter atau fisioterapi sebanyak 2 kali yang dilakukan baik kepada pasien itu sendiri ataupun kepada keluarga atau orang di dekat pasien sebagai caregiver. Dalam komunikasi dengan pasien dibahas mengenai perkembangan terakhir kesehatan pasien, latihan-latihan yang harus dilakukan dan biasanya ini disertai latihan, obat serta makanan yang harus dikonsumsi dan lain-lain. Sedangkan respon yang diberikan oleh pasien adalah menyambut baik dan penuh antusias komunikasi yang dilakukan oleh dokter atau fisioterapi.

Dari hasil komunikasi tersebut maka terdapat dua indikator sebagaimana yang ditegaskan oleh Metta Rahmadiana untuk mengetahui tingkat kepatuhan pasein yaitu understand atau pemahaman akan isu-isu kesehatan atau masalah-masalah kesehatan yang dihadapi dan mengingat (memorize) saran medis yang diberikan. Dari wawancara tersebut maka diperoleh hasil sebagai berikut:

Untuk kemampuan memahami, maka diperoleh data bahwa sebagain besar cukup memahami sedangkan sisanya tidak memahami.

\section{UNDERSTAND}

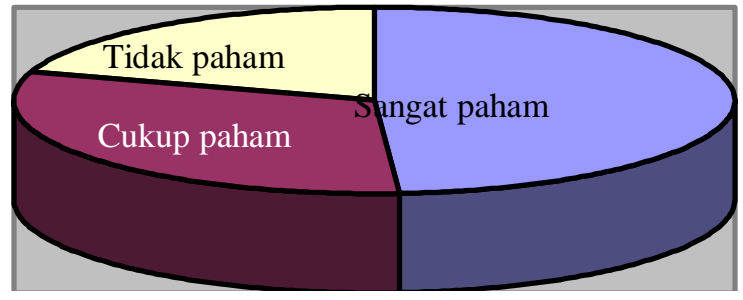

Gambar 3.

Perbandingan tingkat pemahaman pasien terhadap isu-isu kesehatan

Untuk kemampuan mengingat, sebagian besar pasien cukup mampu mengingat dan sisanya tidak mampu mengingat saran media atau latihan yang diberikan. 


\section{MEMORIZE}

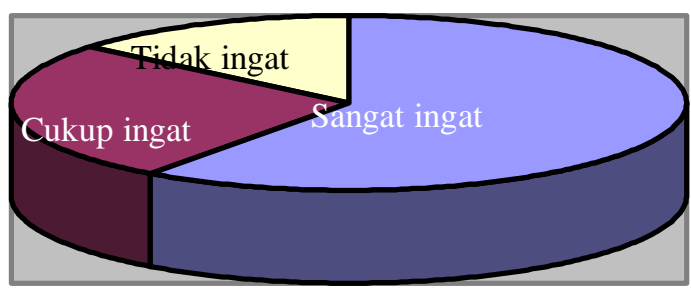

Gambar 4.

Perbandingan tingkat pemahaman pasien terhadap isu-isu kesehatan

\section{KESIMPULAN}

Dari tingkat pemahaman dan ingatan pasien yang menjadi indikator dalam penelitian ini maka dapat dinyatakan sebuah komunikasi kesehatan yang baik harus dilakukan dalam durasi yang cukup dengan melibatkan semua pihak baik itu pasien maupun keluarga pasien atau caregiver. Dalam komunikasi yang dilakukan harus diberikan informasi seluas-luasnya kepada pasien maupun keluarga mengenai perkembangan pasien serta saran-saran medis lainnya. Disisi lain respon positif dari pasien dan keluarga juga menjadi faktor penting agar sebuah komunikasi dapat berjalan dengan baik.

Pada dasarnya ada dua alat ukur utama dalam melihat kepatuhan pasien yaitu kemampuan memahami atau understand dan kemampuan mengingat atau memorize. Dua alat ukur ini sekaligus menjadi indikator efektifitas komunikasi kesehatan yang dilakukan. Dalam penelitian ini efektifitas komunikasi bagi peningkatan kepatuhan pasien terbukti melalui kemampuan memahami dan kemampuan mengingat pasien yang berada pada angka $80 \%$ untuk kemampuan memahami dan $86 \%$ untuk kemampuan mengingat. Itu artinya bahwa telah terjadi kepatuhan pasien terhadap saran-saran medis yang diberikan oleh dokter atau fisioterapi. 


\section{DAFTAR PUSTAKA}

Bungin, B., 2010. Penelitian Kualitatif. 1 ed. Jakarta: Kencana.

Creswell, J. W., 2010. Research Design Pendekatan Kualitatif, Kuantitatif, dan. Yogyakarta: Pustaka Pelajar.

Keputusan Menteri Kesehatan Nomor 378/Menkes/SK/IV/2008 tentang Pedoman Pelayanan

Rehabilitasi Medik Di Rumah Sakit. Jakarta: Kementerian Kesehatan Republik Indonesia.

Kristianingrum, Yetti dkk. 2011. Dukungan Keluarga dan Kepatuhan Minum Obat Pada Orang dengan Diabetes Mellitus. Psycho Idea.Tahun 9, No.2.

Kozier. Erb, Berman. Snyder. 2010. Buku Ajar Fondamental Keperawatan: Konsep, Proses \& Praktik, Volume : 1, Edisi : 7. Jakarta:EGC.

Liliweri, Alo. 2008. Dasar-Dasar Komunikasi Kesehatan. Yogyakarta: Pustaka pelajar

National Center for Health Statistics.Healthy People 2010 Final Review.Hyattsville, MD.2012.

Peraturan Menteri Kesehatan Republik Indonesia Nomor 340/MENKES/PER/III/2010 tentang kalsifikasi Rumah Sakit. Jakarta: kementarian Kesehatan Republik Indonesia.

Pratita, Nurina D. Hubungan Dukungan Pasangan dan Health Locus Of Control dengan Kepatuhan dalam Menjalani Proses Pengobatan pada Penderita Diabetes Mellitus Tipe-2. Surabaya: Jurnal Ilmiah Mahasiswa Universitas Surabaya, 2012.

Rahmadiana, M., 2012. Komunikasi Kesehatan: Sebuah Tinjauan. Jurnal Psikogenesi. Vol. 1, No. 1/Desember 2012.

Rencana Strategis Bisnis Tahun 2015 - 2019 Rumah Sakit Umum Pusat Prof. Kandou Manado, Revisi III. 2015. Manado: RSUP Prof. Kandou. 